\title{
Relationship between ventricular size, white matter injury, and neurocognition in children with stable, treated hydrocephalus
}

\author{
Abhaya V. Kulkarni, MD, PhD, ${ }^{1}$ Ruth Donnelly, PhD, ${ }^{2}$ Donald J. Mabbott, PhD, ${ }^{2}$ and \\ Elysa Widjaja, MD³
}

\begin{abstract}
Divisions of ${ }^{1}$ Neurosurgery, ${ }^{2}$ Psychology, and ${ }^{3}$ Diagnostic Imaging, Hospital for Sick Children, University of Toronto, Ontario,
\end{abstract} Canada

\begin{abstract}
OBJECT Larger-than-normal ventricles can persist in children following hydrocephalus treatment, even if they are asymptomatic and clinically well. This study aims to answer the following question: do large ventricles result in brain injuries that are detectable on diffusion tensor imaging (DTI) and/or in measurable neurocognitive deficits in children with stable, treated hydrocephalus that are not seen in children with small ventricles?
\end{abstract}

METHODS For this prospective study, we recruited 23 children (age range 8-18 years) with hydrocephalus due to aqueductal stenosis or tectal glioma who were asymptomatic following hydrocephalus treatment that had been performed at least 2 years earlier. All patients underwent detailed DTI and a full battery of neuropsychological tests. Correlation analysis was performed to assess the relationship between DTI parameters, neurocognitive tests, and ventricular size. The false-discovery rate method was used to adjust for multiple comparisons.

RESULTS The median age of these 23 children at the time of assessment was 15.0 years (interquartile range [IQR] 12.1-17.6 years), and the median age at the first hydrocephalus treatment was 5.8 years (IQR 2.2 months-12.8 years). At the time of assessment, 17 children had undergone endoscopic third ventriculostomy and 6 children had received a shunt. After adjusting for multiple comparisons, there were no significant correlations between any neurocognitive test and ventricular volume, any DTI parameter and ventricular volume, or any DTI parameter and neurocognitive test.

CONCLUSIONS Our data do not show an association between large ventricular size and additional white matter injury or worse neurocognitive deficits in asymptomatic children with stable, treated hydrocephalus caused by a discrete blockage of the cerebral aqueduct. Further investigations using larger patient samples are needed to validate these results. http://thejns.org/doi/abs/10.3171/2015.1.PEDS14597

KEY WORDS hydrocephalus; ventricle; magnetic resonance imaging; diffusion tensor imaging; neuropsychology

$\mathrm{T}$ REATMENTS for hydrocephalus can leave children grossly asymptomatic but with persistently largerthan-normal ventricles. This is particularly true following treatment using endoscopic third ventriculostomy (ETV). ${ }^{25}$ Some clinicians feel that intentionally maintaining large ventricles in children with hydrocephalus reduces the incidence of certain complications, including shunt obstruction, overdrainage symptoms, and the incidence of chronic headache, ${ }^{10,22}$ although the supporting data are mixed.$^{36}$ Additionally, strong evidence obtained using animals indicates that symptomatic ventriculomegaly in untreated hydrocephalus does lead to white matter injury. ${ }^{11-13}$ Regardless, it remains unclear if children who are otherwise asymptomatic with stable, treated hydrocephalus can develop white matter injury or subtle long-term neurocognitive deficits due to large ventricles.

ABBREVIATIONS ADC = apparent diffusion coefficient; DTI = diffusion tensor imaging; ETV = endoscopic third ventriculostomy; FA = fractional anisotropy; FDR = falsediscovery rate; $F O H R$ = frontal and occipital horn ratio; $I Q=$ intelligence quotient; $I Q R=$ interquartile range; $M D=$ mean diffusivity; $R O I=$ region of interest. SUBMITTED October 28, 2014. ACCEPTED January 22, 2015.

INCLUDE WHEN CITING Published online June 5, 2015; DOI: 10.3171/2015.1.PEDS14597.

DISCLOSURE This study was funded by a grant from The Physicians' Services Inc. Foundation. The foundation was not involved in study design or analysis. The authors report no conflict of interest concerning the materials or methods used in this study or the findings specified in this paper. 
Our study aims to answer 2 specific questions about children with asymptomatic, longstanding, stable, treated hydrocephalus: 1) Does the presumed stretching and compression of the surrounding white matter tracts, which are caused by large ventricles, result in brain injury detectable on diffusion tensor imaging (DTI) that is not seen in children with small ventricles? 2) Does this brain injury result in measurable neurocognitive deficits that are not seen in children with small ventricles? As our study population, we enrolled a sample of children whose hydrocephalus was the result of discrete and isolated stenosis or compression of the cerebral aqueduct and who had also been clinically stable and asymptomatic for several years following hydrocephalus treatment using either ETV or shunting.

\section{Methods \\ Patient Identification}

Potential participants were identified by searching a prospectively maintained database of all children who received surgical treatment for hydrocephalus at The Hospital for Sick Children, Toronto, Canada. We included patients who met the following criteria. 1) Participants were aged 8-18 years, because the most dramatic age-related DTI changes develop through about 6 years of age, ${ }^{27,33}$ though some changes can occur later. ${ }^{31}$ 2) Participants' hydrocephalus was due to stenosis or compression of the cerebral aqueduct (i.e., congenital aqueductal stenosis or tectal glioma). Many etiologies of childhood hydrocephalus are associated with brain damage unrelated to the hydrocephalus itself (e.g., brain tumors, meningitis, and congenital brain malformations). Aqueductal stenosis and tectal glioma represent the "purest" forms of hydrocephalus, in that there are likely no other significant brain anomalies or mechanisms of injury other than hydrocephalus itself. 3) Surgical treatment for hydrocephalus (using either a CSF shunt or ETV) was performed at least 2 years prior to study enrollment, with no hydrocephalus revision surgeries within 24 months of study enrollment, as large ventricles due to hydrocephalus can sometimes take many months to settle down to a stable baseline. ${ }^{36}$ 4) Participants had no history of brain operations other than for hydrocephalus treatment or for biopsy of an obstructing lesion, 5) nor a history of chemotherapy or cranial radiation therapy. 6) The patient should be able to undergo MRI without sedation and has no other contraindication to MRI. 7) A parent or primary caregiver is able and willing to provide consent and able to read and write in English.

\section{Data Collection}

We collected patient data after consent was obtained, including patient age and surgical history of hydrocephalus treatment. Imaging and neuropsychological tests were performed as described below.

\section{Imaging Protocol}

Measurements were performed using a GE LX 1.5-T MRI scanner (General Electric Healthcare) and a singlechannel quadrature head coil. Three-dimensional T1weighted SPGR (spoiled gradient-recalled acquisition) sequencing $(\mathrm{TR} / \mathrm{TE}=8.6 / 4.2 \mathrm{msec}, 122$ contiguous axial slices, 1.5 -mm-thick slices, $256 \times 192$ matrix) and proton density/T2-weighted interleaved sequencing (TR/TEPD/ TET $2=2800 / 30 / 90 \mathrm{msec}, 54$ axial slices with $2.5-\mathrm{mm}$ spacing, 5-mm-thick slices, $256 \times 192$ matrix) were included as part of the region of interest (ROI) analyses and to facilitate automatic registration, respectively. DTI was performed using single-shot spin-echo DTI sequencing with an echo planar imaging readout (25 directions, $\mathrm{TR} / \mathrm{TE}=10,000 / 0-79 \mathrm{msec}, 32$ contiguous axial slices, 3 -mm-thick slices, $128 \times 128$ matrix, $\mathrm{b}=1000 \mathrm{sec} / \mathrm{mm}^{2}$, $1 \mathrm{~b}=0$ image). Eddy current correction was conducted on the diffusion-weighted raw data.

\section{DTI Assessment of White Matter}

Images were visually inspected, and slices containing artifacts were removed from tensor calculations. Mean diffusivity (MD) and fractional anisotropy (FA) maps were calculated pixel by pixel by acquiring traces and eigenvalues from the matrices of the diffusion gradients. ${ }^{3,30}$ The regions on each patient's T1-weighted image were classified as gray matter, white matter, and CSF using a priori pediatric probability mapping ${ }^{42}$ and an automated tissue segmentation algorithm (FSL-FAST). ${ }^{48}$ T1-weighted scans were transformed into DTI space using linear and nonlinear algorithms ${ }^{45,46}$ in order to perform ROI analyses using a predefined anatomical template. ${ }^{23}$ The template, which had been modified by Mabbott et al., ${ }^{29}$ included the bilateral frontal, temporal, parietal, and occipital lobes and was applied to each patient's white matter segmentation using affine registration ${ }^{45,46}$ and transformed into DTI space (Fig. 1). In addition to the hemispheric lobar data, the genu and splenium of the corpus callosum were manually traced using Analyze 10.0 (Biomedical Imaging Resource, Mayo Clinic). Each patient's DTI indices (MD and FA) were calculated for the lobar white matter and genu and splenium of the corpus callosum.

\section{Ventricular Assessment}

Ventricular and brain volume were measured using Analyze 10.0. Multistep volume assessment was performed using the tools included with Analyze, including multispectral tissue segmentation, interactive image editing, and counting the pixels with the ROI. The CSF, gray matter, and white matter regions were defined and plotted into a $2 \mathrm{D}$ feature space in which the pixel signal intensity on the T2-weighted sequence is represented on the x-axis, and the pixel signal intensity on the proton density image is represented on the $\mathrm{y}$-axis. The k-nearest neighbor multispectral algorithm was then applied to the pixels of the entire section.

The classified images were edited using the manual trace tool in order to remove pixels representing the calvaria and extracranial soft tissues. The inner table of the skull was used as a landmark for the separation of the intracranial and extracranial compartments. All pixels assigned to each segmented category (gray matter, white matter, and CSF) were then summed throughout all of the classified edited images of the foramen magnum to the vertex. In the second editing step, the subregions that included the lateral ventricles, the lateral horns of the lateral ventricles, and the third and fourth ventricles were manu- 


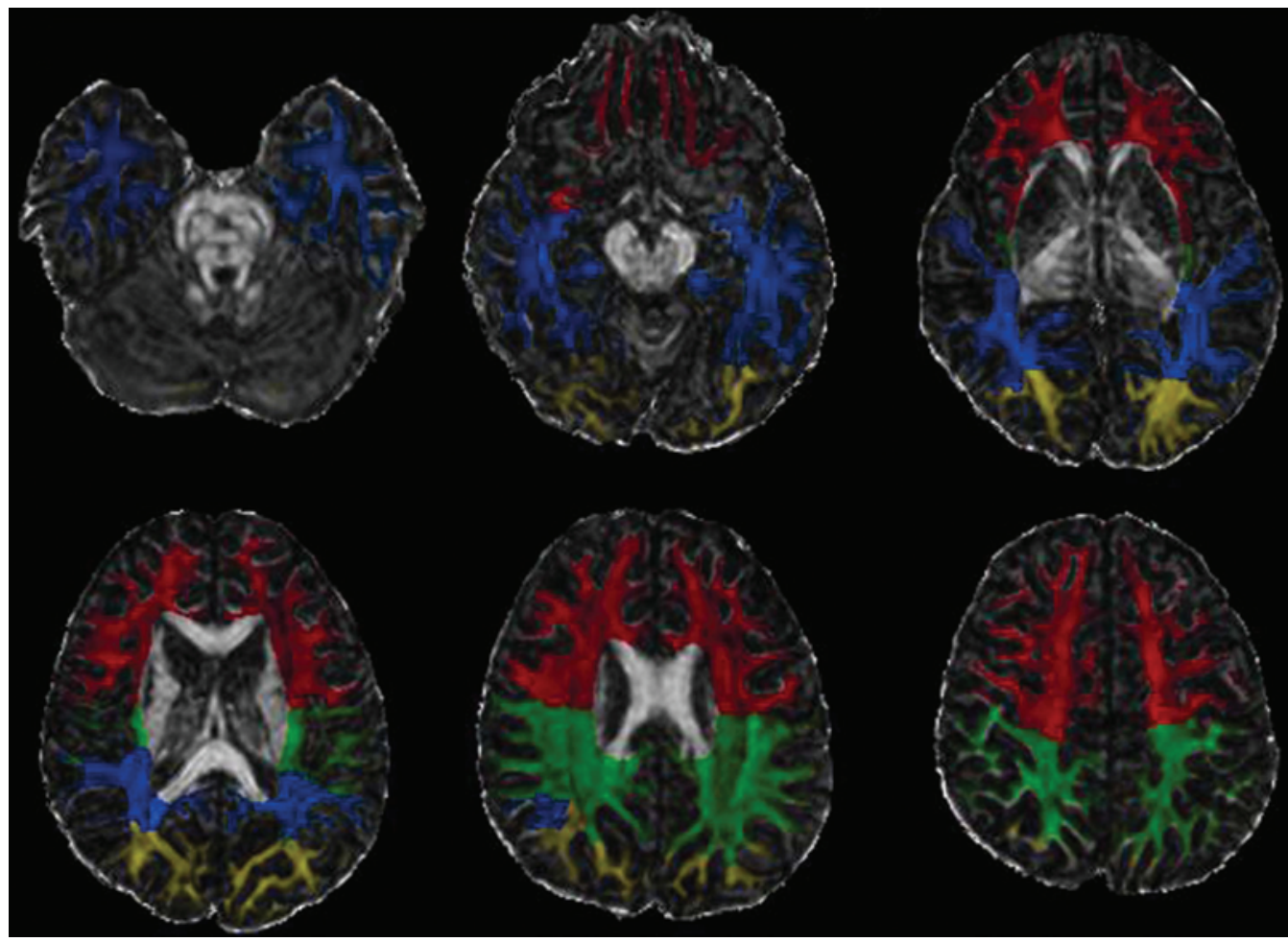

FIG. 1. White matter compartments in the DTI space. White matter segmentations (using FSL-FAST, an automated tissue segmentation algorithm ${ }^{48}$ ) were subdivided into 4 supratentorial compartments (frontal, parietal, temporal, and occipital hemispheres) using an anatomical template that was modified from Kabani et al. ${ }^{23}$ and registered to DTI space. ${ }^{29}$ Yellow, blue, green, and red indicate white matter regions of interest in the occipital, temporal, parietal, and frontal lobes, respectively. Figure is available in color online only.

ally traced. The pixels assigned to CSF in these subregions were also summed. The total ventricular volume was obtained by summing the lateral, third, and fourth ventricles. The total brain volume was obtained by summing the gray and white matter pixels and multiplying by the voxel dimension. The total intracranial volume was determined by summing the total brain and total CSF volume. The ventricular volume index was calculated by dividing the total ventricular volume by the total intracranial volume.

We also measured ventricular size using the frontal and occipital horn ratio (FOHR), which is a previously validated linear measure. ${ }^{26,32}$ We used FOHR to describe the range of ventricular sizes seen in our sample because FOHR is a more commonly understood measure than the ventricular volume index.

\section{Neurocognitive Testing}

Our neuropsychological testing battery was previously described and is repeated here. ${ }^{24}$ The neuropsychological tests were administered by a trained psychological assistant and supervised by an experienced pediatric neuropsychologist. The testing battery included the core tasks of a standard neuropsychological evaluation and an intensive and comprehensive assessment of cognitive functioning. Testing lasted approximately 5 hours and included tests for intelligence (intelligence quotient [IQ]), language, academic performance, memory, visual-motor and visualspatial skills, and visual information-processing speed.

We selected tests from the clinical testing battery avail- able at our institution that are administered to children with hydrocephalus who have been referred to the department of psychology from neurosurgery. If any of the tests could not be appropriately administered to the entire age range included in this study (8-18 years), then we used upward or downward extensions of the tests, which had similar formats and comparable outcome measures.

Most of the included tests have more than 1 outcome score. We selected specific a priori scores that we thought best reflected the child's performance in a particular area of interest. Table 1 lists the abbreviated names, the full names of the administered tests, and the particular scores that were used.

For the first 18 tests listed in Table 1, higher scores indicate stronger performance by the child. The last 3 scores listed were obtained from 2 different parent questionnaires, and higher scores indicate more problems in the queried areas. One score is from a behavioral questionnaire, ${ }^{1}$ which asks the parents about their child's difficulties in areas such as anxiety, depression, socializing, attention, and aggression. The other 2 scores are from an executive function questionnaire, ${ }^{21}$ which asks the parents about their child's everyday functioning in areas such as controlling their behaviors (behavioral regulation score) and planning, organizing, self-monitoring, and paying attention (metacognitive abilities score).

\section{Analysis}

Descriptive statistics were calculated as the mean (SD) 
TABLE 1. Neuropsychological test results

\begin{tabular}{|c|c|c|c|c|c|}
\hline Domain & Test & Description* & Mean† & SD $\ddagger$ & $\begin{array}{l}\text { Correlation wl } \\
\text { Ventriclular Vol } \\
\quad \text { Index }\end{array}$ \\
\hline \multirow[t]{3}{*}{$\begin{array}{l}\text { Intellectual } \\
\text { abilities }\end{array}$} & Verbal IQ Index & $\begin{array}{l}\text { For ages } 8-15.11 \text { yrs, WISC-IV was used to determine the Verbal Com- } \\
\text { prehension Index Score. }{ }^{39} \text { For ages } 16+\text { yrs, WAIS-III was used to } \\
\text { determine the Verbal Comprehension Index Score. } .^{38}\end{array}$ & $101(100)$ & $14(15)$ & -0.01 \\
\hline & Nonverbal IQ Index & $\begin{array}{l}\text { For ages } 8-15.11 \text { yrs, WISC-IV was used to determine the Perceptual } \\
\text { Reasoning Index Score. }{ }^{39} \text { For ages } 16+\text { yrs, WAIS-III was used to } \\
\text { determine the Perceptual Organization Index Score. }{ }^{38}\end{array}$ & $101(100)$ & $16(15)$ & 0.11 \\
\hline & $\begin{array}{l}\text { Processing Speed IQ } \\
\quad \text { Index }\end{array}$ & $\begin{array}{l}\text { For ages } 8-15.11 \text { yrs, WISC-IV was used to determine the Process- } \\
\text { ing Speed Index Score. }{ }^{39} \text { For ages } 16+\text { yrs, WAIS-III was used to } \\
\text { determine the Processing Speed Index Score. }{ }^{38}\end{array}$ & $93(100)$ & $19(15)$ & 0.03 \\
\hline \multirow[t]{4}{*}{ Language } & PPVT & PPVT-III. ${ }^{16}$ Receptive language vocabulary test. & $103(100)$ & $12(15)$ & 0.05 \\
\hline & EOWVT & EOWPVT-2000 Edition. ${ }^{20}$ Expressive language vocabulary test. & $102(100)$ & $12(15)$ & 0.21 \\
\hline & Ambiguous Sentences & STLC-Expanded Edition. ${ }^{41}$ Higher-order language test. & $10(10)$ & $3(3)$ & 0.28 \\
\hline & Oral Comprehension & $\begin{array}{l}\text { Subtest included in WJ-III. Tests for achievement }{ }^{43} \text { \& understanding } \\
\text { orally presented sentences. }\end{array}$ & $102(100)$ & $9(15)$ & 0.27 \\
\hline \multirow[t]{3}{*}{ Academics } & $\begin{array}{l}\text { Letter-Word Identifica- } \\
\text { tion }\end{array}$ & Subtest included in WJ-III. Test for reading individual words. & $101(100)$ & $10(15)$ & 0.06 \\
\hline & Calculation & $\begin{array}{l}\text { Subtest included in WJ-III. Test for performing mathematical calcula- } \\
\text { tions. }\end{array}$ & $90(100)$ & $18(15)$ & 0.15 \\
\hline & $\begin{array}{l}\text { Passage Comprehen- } \\
\text { sion }\end{array}$ & Subtest included in WJ-III. Test for understanding written sentences. & $93(100)$ & $15(15)$ & 0.17 \\
\hline \multirow[t]{6}{*}{ Memory } & Stories Delayed & $\begin{array}{l}\text { For ages } 5-15.11 \text { yrs, CMS, }{ }^{9} \text { stories subtest, \& } 30 \text {-min delayed test } \\
\text { were administered. For ages } 16+\text { yrs, WMS-III, }{ }^{0} \text { stories subtest, } \\
30 \text {-min delayed test were administered. Memory tests for orally } \\
\text { presented stories. }\end{array}$ & $11(10)$ & $3(3)$ & 0.17 \\
\hline & Faces Delayed & $\begin{array}{l}\text { For ages } 5-15.11 \text { yrs, CMS, faces subtest, \& } 30 \text {-min delayed test were } \\
\text { administered. For ages } 16+\text { yrs, WMS-III, faces subtest, \& 30-min } \\
\text { delayed test were administered. Memory test for pictures of faces. }\end{array}$ & $11(10)$ & $3(3)$ & -0.13 \\
\hline & Design Memory & $\begin{array}{l}\text { Subtests included in WRAML-2. }{ }^{34} \text { Tests memory for designs presented } \\
10 \text { sec prior. }\end{array}$ & $8(10)$ & $3(3)$ & -0.11 \\
\hline & Sentence Memory & $\begin{array}{l}\text { Subtest included in WRAML-2. Tests immediate memory for orally } \\
\text { presented sentences. }\end{array}$ & $10(10)$ & $2(3)$ & 0.07 \\
\hline & List Learning & $\begin{array}{l}\text { For ages } 5-15.11 \text { yrs, CVLT-C were administered. }{ }^{15} \text { For ages } 16+\text { yrs, } \\
\text { CVLT-II was administered. } .^{14} \text { Tests memory for listed words recalled } \\
\text { over all } 5 \text { oral presentations of the list. }\end{array}$ & $49(50)$ & $14(10)$ & 0.33 \\
\hline & List Memory Delayed & $\begin{array}{l}\text { For ages } 5-15.11 \text { yrs, CVLT-C was administered. For ages } 16+\text { yrs, } \\
\text { CVLT-2 was administered. Memory for list words free-recalled } 20 \\
\text { min after last recall of the list. }\end{array}$ & $0(0)$ & $2(1)$ & 0.24 \\
\hline Visual-motor & Beery VMI & BBDTVMI-V. ${ }^{4}$ Tests copying geometric shapes \& visual motor skills. & $91(100)$ & $22(15)$ & 0.35 \\
\hline Visual-spatial & Spatial Relations & $\begin{array}{l}\text { Subtest included in the WJ-III for cognitive abilities. }{ }^{44} \text { Tests the ability } \\
\text { to mentally manipulate shapes, but no visual-motor component is } \\
\text { included. }\end{array}$ & $104(100)$ & $13(15)$ & 0.20 \\
\hline \multirow{3}{*}{$\begin{array}{l}\text { Behavior/ } \\
\text { Executive } \\
\text { Function }\end{array}$} & Behavior Problems & $\begin{array}{l}\text { CBCL. }{ }^{1} \text { Behavioral questionnaire filled out by the parent. Total problems } \\
\text { score. }\end{array}$ & $50(50)$ & $11(10)$ & 0.21 \\
\hline & Behavior Regulation & $\begin{array}{l}\text { BRIEF. }{ }^{21} \text { Behavioral questionnaire filled out by the parent. Overall rating } \\
\text { of child's ability to inhibit or shift behavior \& control emotions. }\end{array}$ & $50(50)$ & $13(10)$ & 0.18 \\
\hline & Metacognitive Abilities & $\begin{array}{l}\text { BRIEF. Behavioral questionnaire filled out by the parent. Overall rating } \\
\text { of child's ability to initiate, plan, organize, self-monitor, \& pay atten- } \\
\text { tion. }\end{array}$ & $52(50)$ & $14(10)$ & 0.08 \\
\hline
\end{tabular}


BBDTVMI = Beery Buktenia Developmental Test of Visual-Motor Integration; BRIEF = Behavior Rating Inventory of Executive Function; CBCL = Children's Behavior Checklist; CMS = Children's Memory Scale; CVLT-C = California Verbal Learning Test-Children's Version; EOWVT = Expressive One-Word Picture Vocabulary Test; PPVT = Peabody Picture Vocabulary Test; STLC = Subtest of the Test of Language Competence; WAIS = Wechsler Adult Intelligence Scale; WJ = Woodcock-Johnson; WMS $=$ Wechsler Memory Scale; WISC $=$ Wechsler Intelligence Scale for Children; WRAML $=$ Wide Range Assessment of Memory and Learning.

* Roman or Arabic numerals following abbreviated test names designate editions.

$\dagger$ The numbers outside the parentheses represent the mean values for the study sample. The numbers inside the parentheses represent the mean values for the general population.

$\ddagger$ The numbers outside the parentheses represent the standard deviation values for the study sample. The numbers inside the parentheses represent the standard deviation values for the general population.

or median (interquartile range $[\mathrm{IQR}]$ ). Pearson correlations were used to assess the relationships between ventricular volume, DTI parameters, and neurocognitive tests. Specifically, the following comparisons were made: 1) ventricular volume index versus mean FA and MD in the frontal hemispheric (left and right), temporal hemispheric (left and right), parietal hemispheric (left and right), occipital hemispheric (left and right), and cerebellar hemispheric lobes (left and right), pons/brainstem, and corpus callosum (genu and splenium); 2) the results of all 18 neurocognitive tests versus mean FA and mean $\mathrm{MD}$ in the frontal hemispheric (left and right), temporal hemispheric (left and right), parietal hemispheric (left and right), occipital hemispheric (left and right), cerebellar hemispheric lobes (left and right), pons/brainstem, and corpus callosum (genu and splenium); 3) ventricular volume index versus the results of all 18 neurocognitive tests; and 4) brain volume versus the results of all 18 neurocognitive tests.

Because these evaluations involved multiple comparisons, we adjusted the statistical tests using the false-discovery rate (FDR) method, which is less conservative than Bonferroni correction., 5 Therefore, correlations were only considered significant if the q-value (i.e., the FDR equivalent of the $\mathrm{p}$ value) was $<0.05$.

Analyses were performed using SPSS 22.0 statistical software (IBM SPSS, Inc.).

This study was approved by the research ethics board of the Hospital for Sick Children, Toronto, Ontario, Canada.

\section{Results}

Forty-one potentially eligible patients were found after initially screening our database and clinical records, of whom 32 patients could be reached to discuss participation in this study. Of these, 8 patients refused and 1 patient agreed to participate, but her data could not be used due to significant imaging artifacts. The remaining 23 children $(56 \%)$ formed the population for our analysis. The median age of these 23 children at the time of assessment was 15.0 years (IQR 12.1-17.6 years), and the median age at the first hydrocephalus treatment was 5.8 years (IQR 2.2 months-12.8 years). The etiology of hydrocephalus was tectal glioma (11 patients) or aqueductal stenosis (12 patients). The primary treatment for hydrocephalus was ETV in 18 patients (1 patient also underwent concurrent biopsy due to tectal glioma) or CSF shunting in 5 patients. Following primary surgery, 14 patients required no further hydrocephalus surgeries, 3 patients required 1 revision surgery, and 6 patients required 2 or more revision surgeries. At assessment, 17 patients had an ETV and 6 patients had a shunt.
There was a large range of ventricular sizes in our study population (Fig. 2). Mean and median ventricular size, as measured using FOHR, were 0.45 (SD 0.09) and 0.44 (IQR 0.39-0.53), respectively. For reference, the FOHR of normal-sized ventricles is approximately $0.37 .{ }^{32}$ The mean brain volume was $1539 \mathrm{~cm}^{3}$ (SD 325). Mean ventricular CSF volume was $163.6 \mathrm{ml}$ (SD 163.2), and the mean ventricular volume index was 0.092 (SD 0.082). The FOHR measurement correlated highly with both ventricular CSF volume and the ventricular volume index (both Pearson correlation coefficients $>0.92, \mathrm{p}<0.0001)$.

The DTI parameters for the different brain regions are shown in Table 2.

The results of the neurocognitive tests are shown in Table 1. There was no significant correlation between any of the neurocognitive tests and the ventricular volume index (all Pearson correlation coefficients $<0.35$, all $\mathrm{p}$ values $>0.12$, and all q-values $>0.50$ ). An example is shown
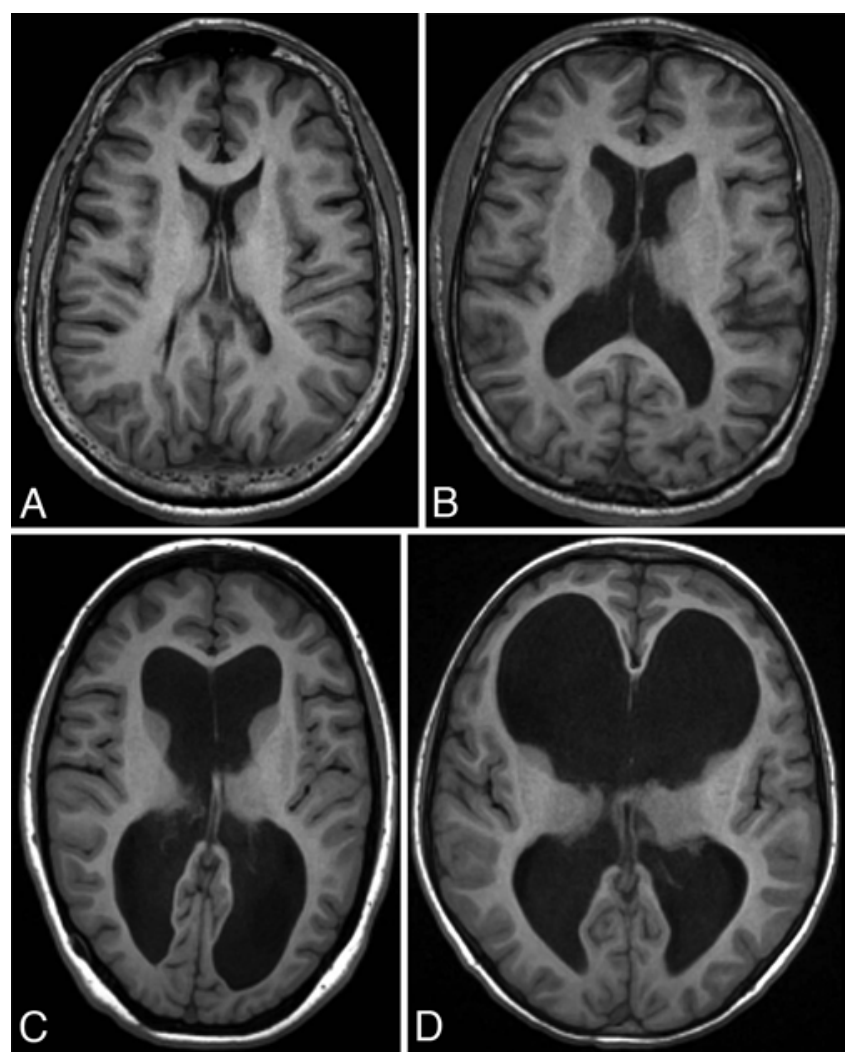

FIG. 2. Axial T1-weighted MR images showing the range in ventricular size. These images represent the following approximate percentiles of ventricular size within our sample: 25 th percentile (A), 50 th percentile (B), 75th percentile (C), and 95th percentile (D). 
TABLE 2. DTI parameters

\begin{tabular}{lcc}
\hline \multicolumn{1}{c}{ Region } & $\mathrm{FA}^{*}$ & $\mathrm{MD}{ }^{*} \dagger$ \\
\hline Left frontal & $0.386 \pm 0.022$ & $0.817 \pm 0.054$ \\
\hline Right frontal & $0.385 \pm 0.024$ & $0.824 \pm 0.057$ \\
\hline Left temporal & $0.389 \pm 0.033$ & $0.821 \pm 0.051$ \\
\hline Right temporal & $0.387 \pm 0.031$ & $0.816 \pm 0.042$ \\
\hline Left parietal & $0.401 \pm 0.026$ & $0.769 \pm 0.040$ \\
\hline Right parietal & $0.401 \pm 0.030$ & $0.771 \pm 0.040$ \\
\hline Left occipital & $0.355 \pm 0.029$ & $0.778 \pm 0.043$ \\
\hline Right occipital & $0.351 \pm 0.025$ & $0.786 \pm 0.036$ \\
\hline Pons/brainstem & $0.458 \pm 0.021$ & $0.763 \pm 0.029$ \\
\hline Corpus callosum (genu) & $0.582 \pm 0.054$ & $0.924 \pm 0.073$ \\
\hline Corpus callosum (splenium) & $0.626 \pm 0.127$ & $0.823 \pm 0.131$ \\
\hline Left cerebellum & $0.367 \pm 0.031$ & $0.670 \pm 0.023$ \\
\hline Right cerebellum & $0.379 \pm 0.030$ & $0.665 \pm 0.022$ \\
\hline * Values are listed as mean $\pm \mathrm{standard} \mathrm{deviation.}^{-3} \mathrm{~mm}^{2} / \mathrm{sec}$. & \\
$\dagger$ The units for MD are $\times 10^{-3}$ &
\end{tabular}

in Fig. 3. Similarly, there was no significant correlation between any of the neurocognitive tests and brain volume (all q-values $>0.20$ ).

After assessing the correlations between ventricular volume index and DTI parameters, and between the DTI parameters and the neurocognitive tests, some comparisons did demonstrate statistically significant correlations on initial testing $(\mathrm{p}<0.05)$. However, no comparisons remained significant after adjusting for multiple comparisons using the FDR method (all q-values >0.55).

\section{Comparison of ETV and Shunts}

We performed post hoc analyses to assess differences in ventricular volume and the neurocognitive test results between patients who had undergone ETV $(n=17)$ and patients with shunts $(n=6)$. Although an association between higher nonverbal IQ (105 vs 89) and larger ventricular volume index (0.11 vs 0.05 ) was suggested among ETV patients, this association was not significant after adjusting for multiple comparisons.

\section{Discussion}

Among asymptomatic children with stable, treated hydrocephalus caused by a discrete blockage of the cerebral aqueduct, our data suggest that there is no convincing evidence that large ventricular size causes additional white matter injury or worse neurocognitive deficits. Post hoc analysis also revealed no obvious differences in white matter integrity on DTI or neurocognitive outcomes between patients who received ETV or shunting. Our study is unique because we included detailed data on asymptomatic patients with long-standing hydrocephalus. Importantly, hydrocephalus was caused by a discrete blockage of the cerebral aqueduct in all patients, so, in theory, the damage to their brains should only have resulted from the ventriculomegaly itself.

Studies conducted in the 1990s, which were primarily performed by Fletcher et al., ${ }^{17-19}$ identified associations between brain morphometry and functioning in children

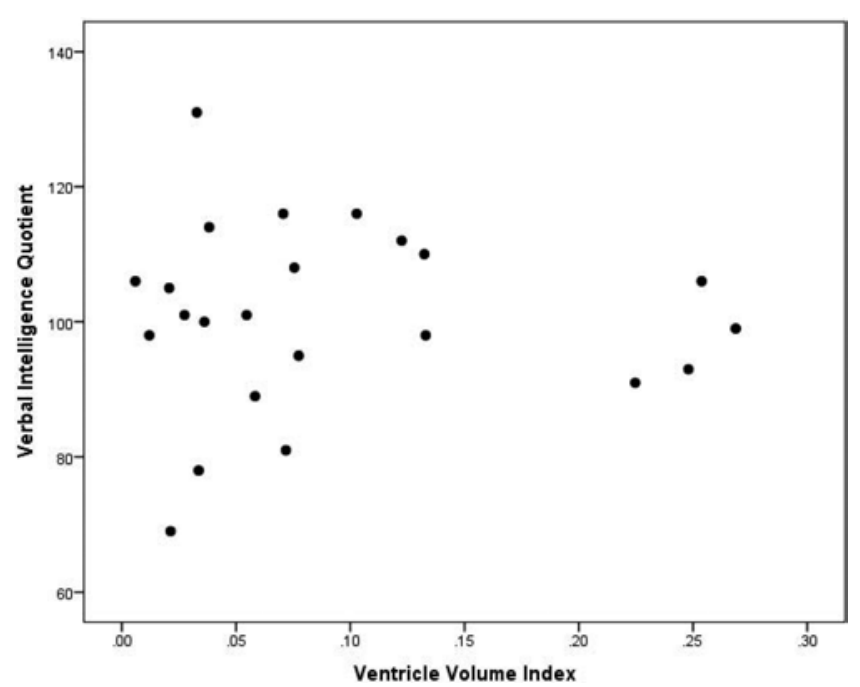

FIG. 3. Scatterplot showing the relationship between ventricular volume index (x-axis) and verbal IQ (y-axis).

with treated hydrocephalus in comparison with controls. For example, deficits in verbal, cognitive, and, especially, nonverbal functioning are correlated with the size of the corpus callosum; nonverbal measures are correlated with size of the right lateral ventricles; verbal measures are correlated with the size of the left lateral ventricle; and enlargement of the posterior portion of the ventricles is correlated with deficits in language, visuospatial, and visuomotor skills.

More recently, DTI has become the most advanced and sensitive method for assessing white matter injury in vivo. In children treated with cranial radiation, or those who were born prematurely, studies have shown associations between abnormal DTI parameters and several aspects of neurocognitive functioning. ${ }^{28,35}$ Regarding pediatric hydrocephalus, most DTI studies to date examined children with new-onset symptomatic hydrocephalus or children who were only recently treated. Ulug et al. found increased apparent diffusion coefficient (ADC) in the periventricular white matter, which implies subtle edema that would not be apparent on other imaging sequences. ${ }^{37}$ ADC generally improves after shunt surgery, but this is correlated with the extent of reduction in ventricular size; i.e., greater reduction in ventricular size is associated with greater ADC reduction. In fact, in a single patient, Ulug et al. reported the progressive decrease in ADC as the ventricles slowly shrank. In successful cases, ADC normalizes within several days after treatment. Assaf et al. found increased FA in the white matter tracts lateral to the ventricles in patients with acute hydrocephalus, which was postulated to occur due to the tighter packing of the compressed tracts. ${ }^{2}$ In the corpus callosum, FA decreased and ADC increased - which is quite typical of white matter injury. After shunt insertion, the FA in the lateral white matter decreased to normal levels, but the changes in the corpus callosum did not improve. This suggests that the corpus callosum is more susceptible to injury and degeneration than the lateral white matter. In a recent study on 15 children with new, untreated hydrocephalus and 17 controls, Yuan et al. reported lower FA and higher MD in 
hydrocephalus patients. In a subsample of 8 infants, they also identified a degree of correlation between MD in the posterior limb of the internal capsule and the Motor Scale of the Adaptive Behavior Assessment System, Second Edition (a parent-reported questionnaire) ${ }^{47}$ Cauley et al., in a study on adult hydrocephalus, found that ventricular size is correlated with radial diffusivity and FA in the corona radiata in acute hydrocephalus patients, but not in healthy individuals or patients who received treatment for chronic hydrocephalus. The axial diffusivity of the corona radiata was correlated with FOHR in all 3 subgroups over a range of ventricular sizes. Of note, this study did not correct for the possibility of multiple testing false positives. ${ }^{8}$

In one of the few available long-term follow-up studies performed on children, Buckley et al. ${ }^{7}$ described a 25-month-old baby with acute hydrocephalus who received ETV and assessments using DTI and preoperative neurocognitive tests through 14-months' postoperation. Buckley et al. reported significant improvements in most postoperative DTI parameters, including very good neurocognitive function despite persistent ventriculomegaly. They suggested that DTI parameters and white matter integrity may be more predictive of neurodevelopmental outcomes than ventricular size. Our study largely supports these findings.

Although our findings need to be validated in future studies, the most important implication is that normalizing ventricular size does not need to be the goal of hydrocephalus treatment. Specifically, in children who meet the accepted clinical criteria for adequately treated hydrocephalus, large ventricles appear to be well tolerated and do not cause sustained white matter injury or neurocognitive deficits. This is especially important given the increasing use of ETV, which generally results in some degree of long-term ventriculomegaly.

\section{Limitations}

Our sample size, although relatively large for this type of study, is still small. Because only 23 patients were enrolled, we could only achieve approximately $95 \%$ power to detect a correlation of 0.8 , and only $50 \%$ power to detect a correlation of 0.6. This assumes an unadjusted alpha value of 0.0007, which approximates an FDR q-value of 0.05 . While our sample of children exhibited a wide range of ventricular sizes, it was generally a very highly functional group that demonstrated neurocognitive test results that were well within normal ranges. Overall, there was little variability in the test scores, and the standard deviations were also largely within the normal ranges for similar populations. This homogeneity makes it harder to detect subtle associations with neurocognition that might also exist. The net effect of all these limitations is that we cannot exclude the possibility that some associations, especially those of small magnitude, might exist between ventricular size, DTI parameters, and neurocognition. Finally, our study did not enroll control individuals because the purpose of this study was to determine if, within a population of stable, treated hydrocephalus patients, there are differences between patients with large or small ventricles. The lack of control individuals limited our ability to determine if some degree of white matter injury was present in all subjects, regardless of ventricular size, in comparison with healthy individuals.

\section{Conclusions}

Our data do not show an association between large ventricular size, additional white matter injury, and worse neurocognitive deficits in asymptomatic children with stable, treated hydrocephalus caused by a discrete blockage in the cerebral aqueduct. Because of limitations in our study size and the limited range of cognitive functions in our sample, further investigations using a larger sample of patients are needed to validate these results.

\section{References}

1. Achenbach TM, Rescorla LA: Manual for the ASEBA School-Age Forms \& Profiles. Burlington: University of Vermont, Research Center for Children, Youth, \& Families, 2001

2. Assaf Y, Ben-Sira L, Constantini S, Chang LC, Beni-Adani L: Diffusion tensor imaging in hydrocephalus: initial experience. AJNR Am J Neuroradiol 27:1717-1724, 2006

3. Bammer R, Acar B, Moseley ME: In vivo MR tractography using diffusion imaging. Eur J Radiol 45:223-234, 2003

4. Beery KE, Buktenica NA, Beery NA: The Beery-Buktenica Developmental Test of Visual-Motor Integration, ed 5. Minneapolis: NCS Pearson, 2004

5. Benjamini Y, Hochberg Y: Controlling the false discovery rate: a practical and powerful approach to multiple testing. $\mathbf{J}$ R Stat Soc B 57:289-300, 1995

6. Bennett CM, Wolford GL, Miller MB: The principled control of false positives in neuroimaging. Soc Cogn Affect Neurosci 4:417-422, 2009

7. Buckley RT, Yuan W, Mangano FT, Phillips JM, Powell S, McKinstry RC, et al: Longitudinal comparison of diffusion tensor imaging parameters and neuropsychological measures following endoscopic third ventriculostomy for hydrocephalus. J Neurosurg Pediatr 9:630-635, 2012

8. Cauley KA, Cataltepe O: Axial diffusivity of the corona radiata correlated with ventricular size in adult hydrocephalus. AJR Am J Roentgenol 203:170-179, 2014

9. Cohen MJ: Children's Memory Scale. San Antonio: The Psychological Corporation, 1997

10. Czosnyka Z, Czosnyka M, Richards HK, Pickard JD: Posture-related overdrainage: comparison of the performance of 10 hydrocephalus shunts in vitro. Neurosurgery 42:327-334, 1998

11. Del Bigio MR: Future directions for therapy of childhood hydrocephalus: a view from the laboratory. Pediatr Neurosurg 34:172-181, 2001

12. Del Bigio MR: Pathophysiologic consequences of hydrocephalus. Neurosurg Clin N Am 12:639-649, vii, 2001

13. Del Bigio MR, Wilson MJ, Enno T: Chronic hydrocephalus in rats and humans: white matter loss and behavior changes. Ann Neurol 53:337-346, 2003

14. Delis D, Kramer JH, Kaplan E, Ober BA: California Verbal Learning Test, ed 2. San Antonio: The Psychological Corporation, 2000

15. Delis D, Kramer JH, Kaplan E, Ober BA: California Verbal Learning Test, Children's Version. San Antonio: The Psychological Corporation, 1994

16. Dunn LM, Dunn LM: Peabody Picture Vocabulary Test, ed 3. Circle Pines, MN: American Guidance Service, 1997

17. Fletcher JM, Bohan TP, Brandt ME, Brookshire BL, Beaver SR, Francis DJ, et al: Cerebral white matter and cognition in hydrocephalic children. Arch Neurol 49:818-824, 1992

18. Fletcher JM, Bohan TP, Brandt ME, Kramer LA, Brookshire 
BL, Thorstad K, et al: Morphometric evaluation of the hydrocephalic brain: relationships with cognitive development. Childs Nerv Syst 12:192-199, 1996

19. Fletcher JM, McCauley SR, Brandt ME, Bohan TP, Kramer LA, Francis DJ, et al: Regional brain tissue composition in children with hydrocephalus. Relationships with cognitive development. Arch Neurol 53:549-557, 1996

20. Gardner MF: Expressive One-Word Picture Vocabulary Test. Novato, CA: Academic Therapy, 2000

21. Gioia GA, Isquith PK, Guy SC, Kenworthy L: Behavior Rating Inventory of Executive Function. Lutz, FL: Psychological Assessment Resources, 2000

22. Hanlo PW, Cinalli G, Vandertop WP, Faber JA, Bøgeskov L, Børgesen SE, et al: Treatment of hydrocephalus determined by the European Orbis Sigma Valve II survey: a multicenter prospective 5-year shunt survival study in children and adults in whom a flow-regulating shunt was used. J Neurosurg 99:52-57, 2003

23. Kabani NJ, Sled JG, Chertkow H: Magnetization transfer ratio in mild cognitive impairment and dementia of Alzheimer's type. Neuroimage 15:604-610, 2002

24. Kulkarni AV, Donnelly R, Shams I: Comparison of Hydrocephalus Outcome Questionnaire scores to neuropsychological test performance in school-aged children. J Neurosurg Pediatr 8:396-401, 2011

25. Kulkarni AV, Drake JM, Armstrong DC, Dirks PB: Imaging correlates of successful endoscopic third ventriculostomy. J Neurosurg 92:915-919, 2000

26. Kulkarni AV, Drake JM, Armstrong DC, Dirks PB: Measurement of ventricular size: reliability of the frontal and occipital horn ratio compared to subjective assessment. Pediatr Neurosurg 31:65-70, 1999

27. Mabbott DJ, Noseworthy M, Bouffet E, Laughlin S, Rockel $\mathrm{C}$ : White matter growth as a mechanism of cognitive development in children. Neuroimage 33:936-946, 2006

28. Mabbott DJ, Noseworthy MD, Bouffet E, Rockel C, Laughlin S: Diffusion tensor imaging of white matter after cranial radiation in children for medulloblastoma: correlation with IQ. Neuro Oncol 8:244-252, 2006

29. Mabbott DJ, Rovet J, Noseworthy MD, Smith ML, Rockel C: The relations between white matter and declarative memory in older children and adolescents. Brain Res 1294:80-90, 2009

30. Mori S, Crain BJ, Chacko VP, van Zijl PC: Three-dimensional tracking of axonal projections in the brain by magnetic resonance imaging. Ann Neurol 45:265-269, 1999

31. Nagy Z, Westerberg H, Klingberg T: Maturation of white matter is associated with the development of cognitive functions during childhood. J Cogn Neurosci 16:1227-1233, 2004

32. O'Hayon BB, Drake JM, Ossip MG, Tuli S, Clarke M: Frontal and occipital horn ratio: A linear estimate of ventricular size for multiple imaging modalities in pediatric hydrocephalus. Pediatr Neurosurg 29:245-249, 1998

33. Rollins NK: Clinical applications of diffusion tensor imaging and tractography in children. Pediatr Radiol 37:769-780, 2007

34. Sheslow D, Adams W: Wide Range Assessment of Memory and Learning, ed 2. Lutz, FL: Psychological Assessment Resources, 2003

35. Skranes J, Vangberg TR, Kulseng S, Indredavik MS, Evensen
KA, Martinussen M, et al: Clinical findings and white matter abnormalities seen on diffusion tensor imaging in adolescents with very low birth weight. Brain 130:654-666, 2007

36. Tuli S, O'Hayon B, Drake J, Clarke M, Kestle J: Change in ventricular size and effect of ventricular catheter placement in pediatric patients with shunted hydrocephalus. Neurosurgery 45:1329-1335, 1999

37. Uluğ AM, Truong TN, Filippi CG, Chun T, Lee JK, Yang C, et al: Diffusion imaging in obstructive hydrocephalus. AJNR Am J Neuroradiol 24:1171-1176, 2003

38. Wechsler D: The Wechsler Adult Intelligence Scale, ed 3. San Antonio, TX: The Psychological Corporation, 1997

39. Wechsler D: Wechsler Intelligence Scale for Children, ed 4. San Antonio, TX: The Psychological Corporation, 2003

40. Wechsler D: Wechsler Memory Scale, ed 3. San Antonio, TX: The Psychological Corporation, 1997

41. Wiig EH, Secord W: Test of Language Competence, Expanded Edition. San Antonio, TX: The Psychological Corporation, 1989

42. Wilke M, Schmithorst VJ, Holland SK: Normative pediatric brain data for spatial normalization and segmentation differs from standard adult data. Magn Reson Med 50:749-757, 2003

43. Woodcock RW, McGrew KS, Mather N: Woodcock-Johnson III Tests of Achievement. Rolling Meadows, IL: Riverside Publishing, 2001

44. Woodcock RW, McGrew KS, Mather N: Woodcock-Johnson III Tests of Cognitive Abilities. Rolling Meadows, IL: Riverside Publishing, 2001

45. Woods RP, Grafton ST, Holmes CJ, Cherry SR, Mazziotta JC: Automated image registration: I. General methods and intrasubject, intramodality validation. J Comput Assist Tomogr 22:139-152, 1998

46. Woods RP, Grafton ST, Watson JD, Sicotte NL, Mazziotta JC: Automated image registration: II. Intersubject validation of linear and nonlinear models. J Comput Assist Tomogr 22:153-165, 1998

47. Yuan W, McKinstry RC, Shimony JS, Altaye M, Powell SK, Phillips JM, et al: Diffusion tensor imaging properties and neurobehavioral outcomes in children with hydrocephalus. AJNR Am J Neuroradiol 34:439-445, 2013

48. Zhang Y, Brady M, Smith S: Segmentation of brain MR images through a hidden Markov random field model and the expectation-maximization algorithm. IEEE Trans Med Imaging 20:45-57, 2001

\section{Author Contributions}

Conception and design: Kulkarni, Donnelly, Mabbott. Acquisition of data: all authors. Analysis and interpretation of data: Kulkarni, Mabbott, Widjaja. Drafting the article: Kulkarni. Critically revising the article: all authors. Reviewed submitted version of manuscript: all authors. Approved the final version of the manuscript on behalf of all authors: Kulkarni. Statistical analysis: Kulkarni. Study supervision: Kulkarni.

\section{Correspondence}

Abhaya V. Kulkarni, Division of Neurosurgery, Hospital for Sick Children, 555 University Ave., Rm. 1503, Toronto, ON M5G 1X8, Canada. email: abhaya.kulkarni@sickkids.ca. 